\title{
Introduction to "Independent Workers: Growth Trends, Categories, and Employee Relations Implications in the Emerging Gig Economy"
}

\author{
Victor G. Devinatz ${ }^{1}$ \\ Published online: 17 December 2018 \\ (C) Springer Science+Business Media, LLC, part of Springer Nature 2018
}

Since 2000, the number of independent workers has been increasing in all industrial and postindustrial nations. For example, in 2006, the U.S. federal government estimated that 42.6 million workers, or $30 \%$ of the labor force, were either independent workers who held temporary jobs, were self-employed or labored in part-time, contract, or various nonstandard positions. By 2020, projections indicate that $40 \%$ of the U.S. labor force will be composed of independent workers.

A new kind of independent worker has emerged in the aftermath of the 2008 Financial Crisis with a concomitant large increase in unemployment during 2008-2009 and the development of advanced technology. This pioneering employment relationship has been categorized as the sharing economy or the gig economy where workers use online platforms, such as Uber, TaskRabbit, and Fiver, on their smartphones to apply for short-term jobs with clients that advertise that they need shelves mounted, an apartment cleaned, a dog walked, a ride to the airport, items shopped for and delivered, etc. The companies that sponsor these online platforms collect a portion of the workers' pay for operating as middlemen who connect buyers and sellers of these services. Gig economy advocates contend that this employment arrangement benefits workers who have the flexibility to complete various tasks during the day while controlling their own work schedules. These proponents also argue that employees can retain their permanent positions while performing gigs for extra cash during their lunch hours or before or after work. Gig economy critics, however, point out that there are darker sides to this type of employment relationship.

In this timely, well-written and interesting "Perspectives" Section article, Dr. Teresa ShukChing Poon, Associate Professor in the Lee Shau Kee School of Business and Administration at The Open University of Hong Kong, discusses and analyzes the growth of independent workers in industrial and post-industrial economies while identifying the emergence of this new type of independent on-demand workers who obtain employment opportunities (gigs) from clients through App-enabled platform companies. Because many of these on-demand

Victor G. Devinatz

vgdevin@ilstu.edu

1 Department of Management \& Quantitative Methods, Illinois State University, Normal, IL 61790-5580, USA 
workers experience inferior working conditions and low wages while lacking standard workplace protections, Dr. Poon points out that these workers have recently participated in collective actions against the platform companies. She concludes her article by examining the implications of these independent workers' collective activities for the future of employee relations.

If any of the journal's readers are interested in responding to any essays published in the "Perspectives" Section or would like to write articles on any topics in the field of employee relations, please do not hesitate to contact me with your proposal. I welcome both practitionerbased and scholarly-based articles written from any one of a variety of theoretical perspectives. I hope that you enjoy this article and find it most illuminating.

Publisher's Note Springer Nature remains neutral with regard to jurisdictional claims in published maps and institutional affiliations. 